\title{
Processing of Reelin by Embryonic Neurons Is Important for Function in Tissue But Not in Dissociated Cultured Neurons
}

\author{
Yves Jossin, Lanrun Gui, and André M. Goffinet \\ Developmental Neurobiology Unit, Université Catholique de Louvain, B1200 Brussels, Belgium
}

Reelin, the protein defective in reeler mutant mice, plays a key role during brain development. Reelin is processed proteolytically at two sites, and the central fragment mimics function in vitro.

Here, we show that processing is functionally important in vivo, a question that could not be addressed in our previous study. New monoclonal antibodies directed against central Reelin block its binding to lipoprotein receptors and perturb cortical development in vitro, confirming the importance of the central fragment that is detected in tissue and body fluids. Processing occurs when Reelin is incubated with embryonic neurons in culture or with their supernatant, but inhibition of processing by a metalloproteinase blocker does not prevent Reelin signaling in neurons. Furthermore, neurons internalize similarly full-length or central Reelin. In contrast, inhibition of processing prevents signaling and perturbs cortical development in cultured embryonic brain slices. Moreover, in vivo, the concentration of central Reelin is dramatically and selectively increased in receptor-deficient tissue, suggesting its specific downregulation after binding to receptors and internalization. We propose that processing by end-migration neurons is required in tissue (where Reelin is likely anchored to the extracellular matrix) to release the central fragment that diffuses locally and signals to target cells, whereas, in vitro, all Reelin forms have indiscriminate access to cells, so that cleavage is not necessary for signaling.

Key words: metalloproteinase; Dab1; VLDLR; ApoER2; monoclonal antibodies; cerebral cortex

\section{Introduction}

Reelin is a large extracellular protein that plays a pivotal role during brain development. Defective Reelin causes the reeler malformation in mice (D'Arcangelo et al., 1995; Tissir and Goffinet, 2003; Jossin, 2004) and lissencephaly in man (Hong et al., 2000). During cortical development, Reelin secreted by CajalRetzius cells in the marginal zone (MZ) acts on cells of the cortical plate (CP), by binding to two lipoprotein receptors, very low density lipoprotein receptor (VLDLR) and apolipoprotein-E receptor type 2 (ApoER2) (D'Arcangelo et al., 1999; Hiesberger et al., 1999; Trommsdorff et al., 1999). The signal is relayed by the Disabled-1 (Dab1) adaptor that docks to receptors (Howell et al., 1997; Sheldon et al., 1997; Ware et al., 1997; Bar et al., 2003) and is tyrosine phosphorylated by Src family kinases after Reelin binding (Arnaud et al., 2003a; Bock and Herz, 2003; Jossin et al., 2003; Kuo et al., 2005).

The Reelin sequence begins with a region with similarity to

Received Sept. 15, 2006; revised March 2, 2007; accepted March 9, 2007.

This work was supported by Actions de Recherches Concertées Grant ARC 02/07-276, Fonds de la Recherche Fondamentale et Collective Grant 2.4504.01, and by the Fondation Médicale Reine Elisabeth, all from Belgium. Y.J. is a postdoctoral researcher with the Fonds National de la Recherche Scientifique, Belgium, and L.G. was on a fellowship from the University of Louvain. We thank Fadel Tissir and Jacques Van Snick for discussion, Isabelle Lambermont and Esther Paitre for technical assistance, Vincent Strooband for advice on epitope mapping, Christian Sindic for human CSF samples, Joachim Herz for lipoprotein receptor constructs, Jon Cooper for Dab1 mutant brain tissue, and Tom Curran for the Reelin cDNA.

Correspondence should be addressed to Dr. André M. Goffinet, Developmental Neurobiology Unit, Université Catholique de Louvain, Avenue E. Mounier, 73, Box DENE 7382, B1200 Brussels, Belgium. E-mail: Andre. Goffinet@dene.ucl.ac.be.

D0I:10.1523/JNEUROSCI.0023-07.2007

Copyright $\odot 2007$ Society for Neuroscience $\quad 0270-6474 / 07 / 274243-10 \$ 15.00 / 0$
F-spondin, followed by eight repeats of 350-390 residues. Reelin is cleaved in vivo at two sites located $\mathrm{C}$ terminal to domains 2 and 6 , respectively, generating a total of six predicted proteins (Lambert de Rouvroit et al., 1999; Ignatova et al., 2004). We and others showed that a protein composed of central repeats 3-6 recapitulates most functions of Reelin during cortical development (Jossin et al., 2004; Nogi et al., 2006). Thus far, however, central Reelin could not be detected directly in tissue, and the physiological significance of processing in vivo remains unclear. These are important issues, especially because results obtained with the function-blocking antibody CR50 point to the importance of the $\mathrm{N}$-terminal region and studies of Reelin in human pathology have been performed using antibody 142 that probes the same region.

To further study the functional role of Reelin processing, we raised new antibodies against central Reelin repeats and showed that the predicted central fragment is indeed present in the embryonic brain and CSF. These antibodies perturbed the organization of the CP in cultured slices, by interfering with binding of Reelin to receptors and Dab1 phosphorylation, confirming the importance of the central region. Cultured cortical neurons secreted a metalloproteinase that cleaved exogenously added Reelin. However, blocking processing by a metalloproteinase inhibitor did not affect the ability of Reelin to stimulate Dab1 phosphorylation in neurons, in which full-length and central Reelin were internalized similarly. In contrast, inhibition of metalloproteinases in organotypic brain slices decreased Reelin cleavage and signaling and induced a reeler-like phenotype. Moreover, the concentration of central Reelin was specifically and dramatically increased in brains from double VLDLR and 
ApoER2 receptor-deficient mice, suggesting preferential downregulation by target cells in vivo.

These data suggest that cleavage does not influence function when target cells are directly accessible to Reelin but is nonetheless important in tissue. We hypothesize that, in vivo, Reelin is anchored to the extracellular matrix (ECM) and that a metalloproteinase secreted by migrating neurons releases central Reelin, which diffuses locally and binds to receptors on target cells.

\section{Materials and Methods}

Animals. Animal procedures were performed in accordance with institutional guidelines and ratified by competent animal ethics committees. Normal CD1, Reln ${ }^{\text {Orl }}$ (reeler), Dab1 ${ }^{\text {Scm }}$ (Scrambler), VLDLR, and ApoER2 mutant mice were bred in standard conditions. Embryonic development proceeds somewhat more rapidly in CD1 than in inbred mouse strains. Therefore, to obtain embryonic brains precisely at the preplate stage [embryonic day 13 (E13)], a CD1 colony was maintained on an inverted light cycle (lights “off” from 7:00 A.M. to 5:00 P.M.), and females were inspected for the presence of vaginal plugs between 5:00 and 7:00 P.M. Dab1-/- mutant brains were provided by J. Cooper (Fred Hutchinson Cancer Research Center, Seattle, WA).

Monoclonal antibodies. For antigen preparation, a cDNA sequence corresponding to nucleotides 5668-6627 from mouse reelin (GenBank accession number GI 6755311) was amplified with primers, 5'-GCGGATCCGTTCCTGTTGTTCCTCTTCC-3' (forward, BamHI site underlined) and 5'-GCAAGCTTCAGCAGGATAAAATCCCTGG-3' (reverse, EcoRI site underlined), and cloned in pTrcHisA (Invitrogen, San Diego, CA). The encoded polypeptide, named 4B5A, contains residues 1796-2115 of Reelin (GenBank accession number GI 6755312). It contains subrepeats 4B and 5A but excludes epidermal growth factor motifs that were found to hamper expression in bacteria. After induction by isopropyl $\beta$-D-1thiogalactopyranoside, the 4B5A protein was enriched from bacterial extracts using an Ni-NTA affinity column (Qiagen, Chatsworth, CA) (Ausubel, 2001) and further purified to homogeneity by SDS-PAGE and electroelution using a Model 422 apparatus (Bio-Rad, Hercules, CA). Protein 4B5A was used to immunize homozygous $\operatorname{Reln}^{\mathrm{Orl}}$ mice, from which monoclonal antibodies were generated by splenocyte fusion (de Bergeyck et al., 1998). Hybridomas were screened by ELISA and characterized using standard protocols (Ausubel, 2001), and isotypes were defined using the Isostrip kit (Roche, Basel, Switzerland).

Western blots and immunohistochemistry. Samples of human CSF were obtained at the Laboratory of Neurochemistry, Université Catholique de Louvain. Before analysis by SDS-PAGE, samples were concentrated 5- to 10-fold using centrifugal filters (50K NMWL; Millipore, Bedford, MA) (Ignatova et al., 2004). Brain homogenates were prepared in ice-cold PBS with ETDA ( $5 \mathrm{~mm}$ ) supplemented with a protease inhibitor mixture (Complete; Roche). Western blots were performed with anti-Reelin G10 or 142, directed against the $\mathrm{N}$-terminal region, or a mix of antibodies 12 and $14(12+14)$ that recognize epitopes in the C-terminal region (de Bergeyck et al., 1998). Signal was detected using HRP-coupled goat antimouse antibodies (Dako Cytomation, High Wycombe, UK) and the Super Signal West Pico kit (Pierce, Rockford, IL). For immunohistochemistry, brains were fixed in Bouin's fluid, and paraffin sections were incubated with antibodies and processed using the StreptABComplex/ HRP Duet kit (Dako Cytomation). Primary antibodies were antibromodeoxyuridine (BrdU; Becton Dickinson, Mountain View, CA), polyclonal rabbit anti-Tbr1 (gift from Dr. R. Hevner, University of Washington, Seattle, WA), and anti-chondroitin sulfate CS-56 (Sigma, St. Louis, MO). For immunofluorescence, cells were fixed in paraformaldehyde (4\% in PBS), permeabilized with $0.3 \%$ saponin, and incubated with antibody R4B or anti-Reelin E4 (de Bergeyck et al., 1998), followed by fluorescein-labeled antibodies against mouse IgG (Sigma).

Recombinant Reelin proteins, receptor pulldown, and Dab1 phosphorylation assays. The production of recombinant Reelin proteins was described previously (Jossin et al., 2004). The binding to lipoprotein receptors was assessed in pull-down assays with soluble ectodomains of human LDLR, human VLDLR, and mouse ApoER2, produced as soluble fusion proteins with the Fc fragment or His tags, as described previously (Hiesberger et al., 1999). The ability of Reelin to stimulate Dab1 tyrosine phosphorylation in primary neuronal cultures was assessed by immunoprecipitation of Dab1 with a polyclonal antibody, followed by Western blotting and revelation with the $4 \mathrm{G} 10$ antiphosphotyrosine antibody (Upstate Biotechnology, Lake Placid, NY) or with an anti-Dab1 antibody (E1), as described previously (Howell et al., 1999; Jossin et al., 2004).

Primary neuronal and embryonic slice cultures. For primary neuronal cultures, E16.5 fetal brains were dissected in cold calcium- and magnesium-free Hanks solution supplemented with $0.6 \%$ glucose $(\mathrm{HBSS}+\mathrm{G})$. Hemispheres were isolated, and ganglionic eminences, olfactory bulbs, and meninges were discarded to leave mostly the cerebral cortex. Cortices were dissociated with trypsin (Invitrogen) for $5 \mathrm{~min}$ at $37^{\circ} \mathrm{C}$. After trituration with a fire-polished Pasteur pipette, samples were washed in HBSS $+\mathrm{G}$ and triturated in $1 \mathrm{ml}$ of DMEM/F-12 (Cambrex 
A
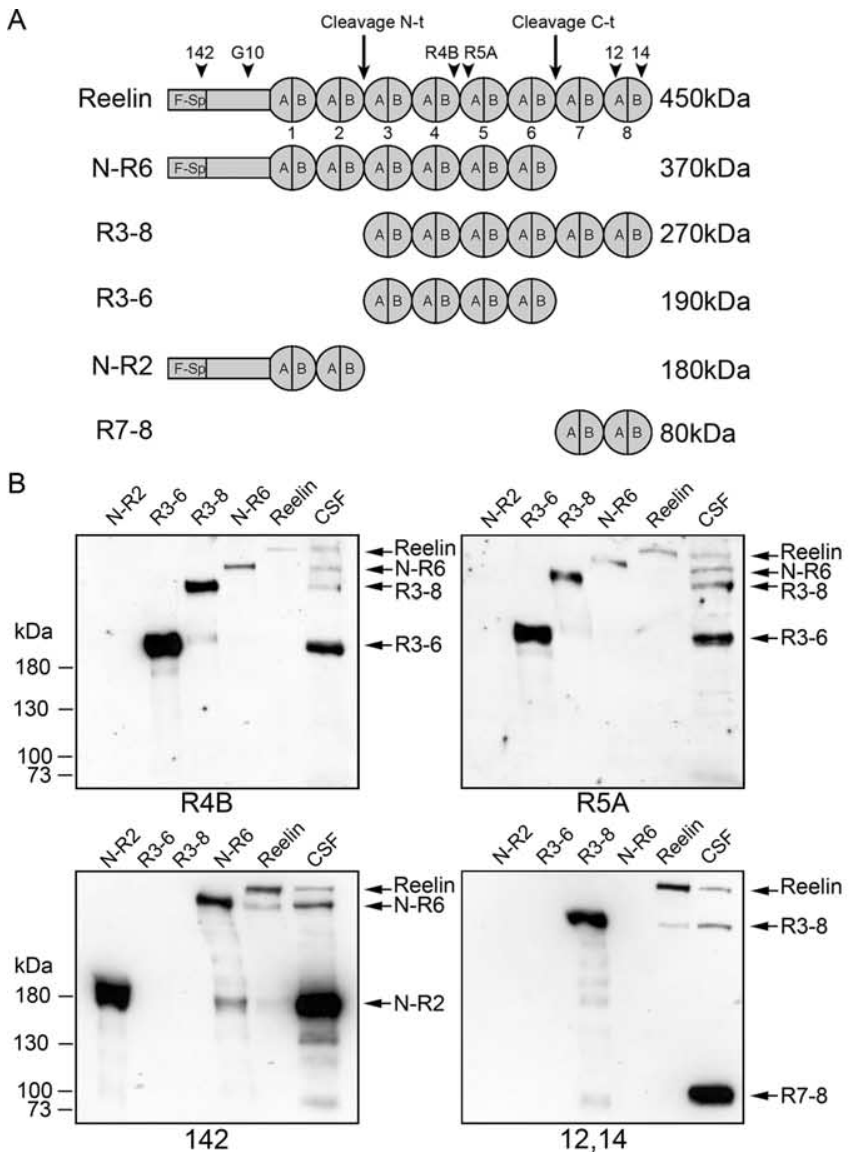

C
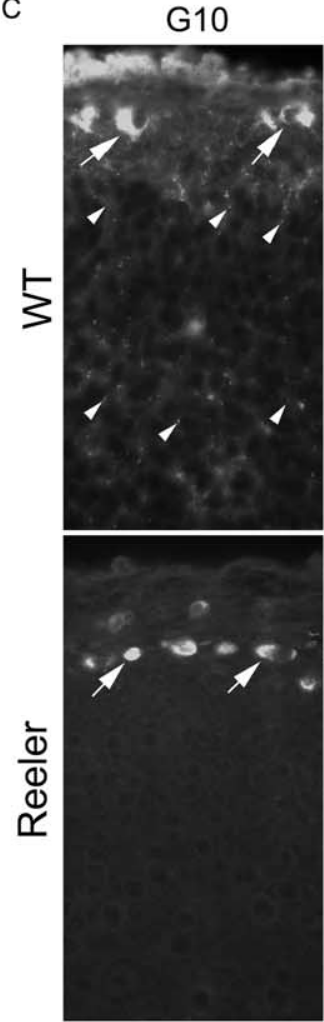

R4B
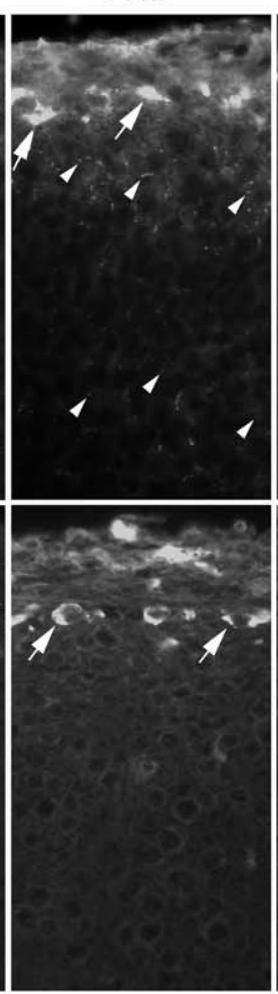

12,14

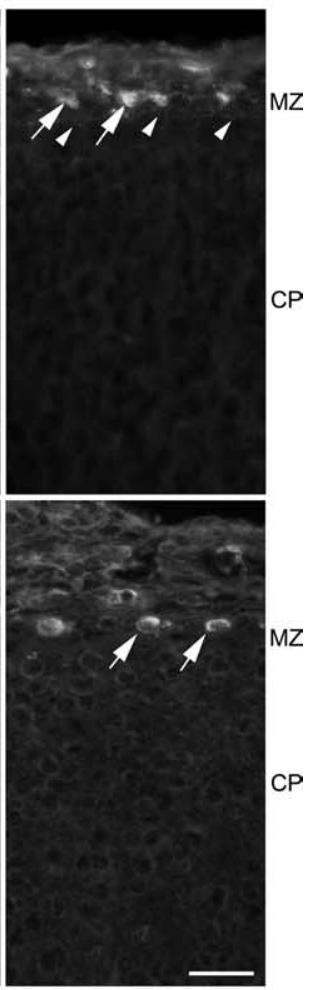

Figure 2. Pattern of Reelin processing. $A$, Reelin is cleaved at two sites ( $\mathrm{N}-\mathrm{t}$ and $\mathrm{C}-\mathrm{t}$ ), thus generating five different fragments in addition to the native polypeptide. Arrowheads point to the epitopes of the antibodies used in this study $(142, \mathrm{G} 10, \mathrm{R} 4 \mathrm{~B}, \mathrm{R} 5 \mathrm{~A}, 12,14)$. F-Sp, Region with similarity to F-spondin. Repeats $1-8$ are schematized as circles, with subrepeats A and B separated by epidermal growth factor motifs (vertical bar). $B$, Western blot of human CSF samples probed with antibodies R4B and R5A, 142, or 12+14. Supernatants from cells transfected with plasmid encoding different fragments (N-R2, R3-6, R3-8, N-R6) and full-length Reelin were loaded for reference. C, Sections in neocortex from wild-type (WT) and reeler mice at postnatal day 0, stained by immunofluorescence with the $\mathrm{G} 10$ ( $\mathrm{N}$-terminal), R4B (central), and 12,14 (C-terminal) antibodies. Cajal-Retzius cells are strongly labeled in all sections (arrows). Immunopositive dots are detected in WT but not in reeler sections, indicating that they correspond to extracellular Reelin (arrowheads). In the MZ, all three antibodies reveal extracellular Reelin, whereas only N-terminal and central epitopes are detected in the CP. Scale bar, $25 \mu \mathrm{m}$.

BioWhittaker, Walkersville, MD) containing $0.025 \%$ DNase I and 0.4 $\mathrm{mg} / \mathrm{ml}$ soybean trypsin inhibitor (Invitrogen). Cells were washed in DMEM/F-12 and plated in 12-well plates coated with ECL cell attachment matrix (entactin, collagen IV, and laminin; Upstate Biotechnology), at a density of 1 million cells per well, in DMEM/F-12 supplemented with B27 (Invitrogen). Metalloproteinases were inhibited by adding GM6001 (Calbiochem, La Jolla, CA) at a concentration of $80 \mu \mathrm{M}$, and the GM6601-negative control (Calbiochem) was used at the same concentration.

The embryonic slice culture system was described previously (Jossin et al., 2003). Briefly, vibratome sections from E13 embryonic brains were cultured on collagen-coated polytetrafluoroethylene membranes (Transwell-COL, catalog \#3494; Costar, Cambridge, MA) for $2 \mathrm{~d}$ in DMEM/F-12 supplemented with B27 and G5 (Invitrogen). Slices were cultured in a chamber (MIC-101; Billups-Rothenberg, Del Mar, CA) gassed with water-saturated $95 \% \mathrm{O}_{2}-5 \% \mathrm{CO}_{2}$. Antibodies were dropdialyzed (VSWP02500 membranes; Millipore) against culture medium and added at an IgG concentration between 0.2 and $1 \mathrm{mg} / \mathrm{ml}$. For S-phase labeling, BrdU (Sigma) dissolved in $0.9 \% \mathrm{NaCl}$ was administered intraperitoneally to pregnant mice at a dose of $20 \mu \mathrm{g} / \mathrm{g}$ body weight, at E10 for labeling of preplate cells or at E13 for analysis of cortical layering.

Data editing. Figures prepared from morphological preparations and scanned gels were edited using Photoshop (Adobe Systems, San Jose, CA).

\section{Results}

Novel monoclonal antibodies R4B and R5A are directed against the central fragment of Reelin

After immunization of reeler mutant mice with protein $4 \mathrm{~B} 5 \mathrm{~A}$ (see Materials and Methods), two IgG2b monoclonal antibodies were selected and named R4B and R5A because they are directed, respectively, against repeats $4 \mathrm{~B}$ and $5 \mathrm{~A}$. Using Western blot analysis of supernatants from HEK293T cells transfected with different constructs, the R4B and R5A epitopes were mapped to sequences 1810-1825 and 1985-2058, respectively (data not shown). When applied to mouse brain sections, R4B and R5A detected immunopositive cells similar to those stained with validated anti-Reelin antibodies (Ogawa et al., 1995; de Bergeyck et al., 1998), or revealed by in situ hybridization with Reelin probes (Schiffmann et al., 1997; Alcantara et al., 1998). They reacted with Cajal-Retzius cells in the MZ of the neonatal cortex and in postnatal brains, with a subset of cortical interneurons, mitral and external granule cells in the olfactory bulb, neurons in the strata lacunosum moleculare and oriens of the hippocampus, and the hilus of the dentate gyrus (Fig. 1). Human CSF samples and mouse brain extracts were analyzed in Western blot with R4B and 
R5A and with antibodies 142 and $12+14$ that react, respectively, with the $\mathrm{N}$ - and C-terminal regions (de Bergeyck et al., 1998; Ignatova et al., 2004) (Fig. 2 A). Fulllength and the following Reelin proteins were used as references: R3-6 ("repeats 3-6", amino acids 1220-2664); R3-8 ("repeats 3-8", amino acids 1220-3428); N-R6 ("N-terminal to end of repeat 6", amino acids 1-2712); N-R2 ("N-terminal to end of repeat 2", amino acids 1-1286); R7-8 (repeats 7 and 8, amino acids 26613428). In CSF, antibodies R4B and R5A reacted with Reelin proteins that contain the sequence $4 \mathrm{~B} 5 \mathrm{~A}$, particularly a protein of $\sim 190 \mathrm{kDa}$ that comigrated with R3-6 (Fig. 2B).

To assess whether processing might influence the diffusion of Reelin fragments in tissue, we examined postnatal day 0 wild-type cortex by immunofluorescence with antibodies against N-terminal (G10), central (R4B), and C-terminal $(12,14)$ epitopes. As shown in Figure 2C, all three antibodies labeled intracellular Reelin in Cajal-Retzius cells as well as punctuate structures in the MZ. The latter are not detected in reeler mice, in which Reelin is not secreted (de Bergeyck et al., 1997), and correspond to extracellular Reelin, possibly Reelin oligomers or aggregates (Utsunomiya-Tate et al., 2000; Kubo et al., 2002). Intriguingly, extracellular Reelin was detected between CP cells with $\mathrm{N}$-terminal and central, but not C-terminal, antibodies. This indicates that full-length Reelin is predominantly located in the MZ and that N-terminal and central fragments are both able to diffuse in the $\mathrm{CP}$ after cleavage.

\section{Antibodies R4B and R5A block Reelin functions in vitro}

The effect of R4B and R5A on the binding of Reelin to lipoprotein receptors was assessed in pull-down reactions. Incubation of Reelin with R4B, but not with control antibodies such as G10 or 142 (N-terminal region) or $12+14$ (C-terminal region), prevented binding to VLDLR-Fc and ApoER2-Fc recombinant proteins (Fig. $3 A$ ). Similar results were obtained with antibody R5A and by using VLDLR-His and ApoER2-His proteins (data not shown). Furthermore, the ability of Reelin to stimulate Dabl phosphorylation in neuronal cultures was drastically decreased by preincubation with R4B (Fig. $3 B$ ) or R5A but not with control antibodies. Finally, when slices from wild-type embryonic brains were cultured for $2 \mathrm{~d}$ in the presence of R4B (Fig. 3C) or R5A, either separately or in combination, their development resembled that of slices prepared from Reelin-deficient embryos. The MZ was not sharply defined, and the CP was disorganized. In contrast, development proceeded normally in slices incubated with the G10 antibody.

A

C
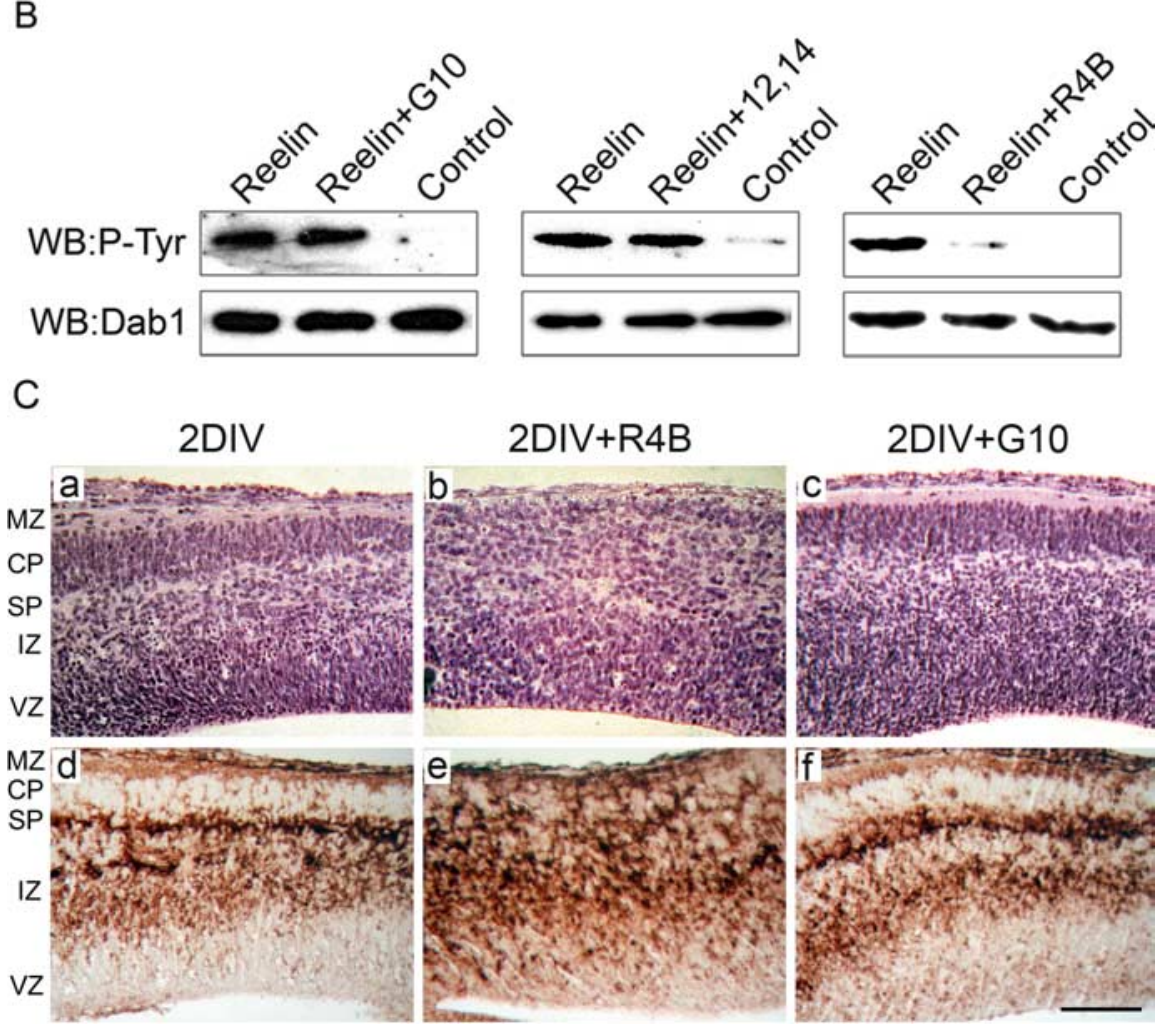

Figure 3. Antibody R4B inhibits Reelin-liporeceptor binding $(\boldsymbol{A})$ and Reelin-induced Dab1 phosphorylation $(\boldsymbol{B})$ and interferes with CP formation in brain slices (C). $\boldsymbol{A}$, Ectodomains of VLDLR-Fc, ApoER2-Fc, and LDLR-Fc (negative control) were adsorbed to protein A-agarose beads. Beads were incubated with Reelin (control) or with Reelin preincubated with antibodies $\mathrm{G10}, 12+14$, or R4B (comparable results were obtained with R5A). Coprecipitates were eluted, processed for Western blot, and probed with anti-Reelin $\mathrm{G} 10$. Whereas Reelin binds to its receptors in the presence of $\mathrm{G} 10$ or $12+14$, the R4B antibody blocks this interaction. Similar results were obtained with receptor ectodomains fused to a His tag and adsorbed to Ni-NTA beads. $\boldsymbol{B}$, Cultured cortical neurons were stimulated with Reelin or Reelin preincubated with antibodies $\mathrm{G} 10,12+14$, or R4B (similar results were obtained R5A). Dab1 was immunoprecipitated and assessed for tyrosine phosphorylation (P-Tyr). Reelin stimulates Dab1 phosphorylation in the presence of $\mathrm{G} 10$ or $12+14$ but not R4B. WB, Western blot. C, Slices from 13-d-old embryonic brains were cultured for $2 d(2 D I V)$ in the presence of R4B or the control antibody $G 10$. Development proceeds normally in the control situation $(\boldsymbol{a}, \boldsymbol{d})$, with a radially organized, dense (P located between the clearly defined $M Z$ and subplate $(S P)$. In slices incubated with $R 4 B(\boldsymbol{b}, \boldsymbol{e})$, the developing CP is disorganized, and the MZ and SP are poorly defined, like in reeler mutant mice (comparable results were obtained with R5A and with the mix R4B and R5A). Incubation with $\mathrm{G} 10(\boldsymbol{c}, \boldsymbol{f})$ does not perturb slice development. $\boldsymbol{a}-\boldsymbol{c}$, Hematoxylin and eosin staining; $\boldsymbol{d}-\boldsymbol{f}$, immunostaining of chondroitin sulfate proteoglycans, a preplate marker. Scale bar, $100 \mu \mathrm{m}$. VZ, Ventricular zone; SP, subplate; IZ, intermediate zone.

Staining with a chondroitin sulfate antibody that labels the cortical preplate showed that incubation with $\mathrm{R} 4 \mathrm{~B}$ or $\mathrm{R} 5 \mathrm{~A}$ prevented preplate splitting, another hallmark of reelin deficiency (Caviness, 1982). These results suggest R4B and R5A block Reelin function.

Cultured neurons secrete a Reelin-processing activity

To examine the effect of neurons on processing, full-length Reelin was incubated for $20 \mathrm{~min}$ at $37^{\circ} \mathrm{C}$ in the presence of embryonic cortical cells, their supernatant, or culture medium alone, after which the pattern of Reelin cleavage was examined. Preparations 
A

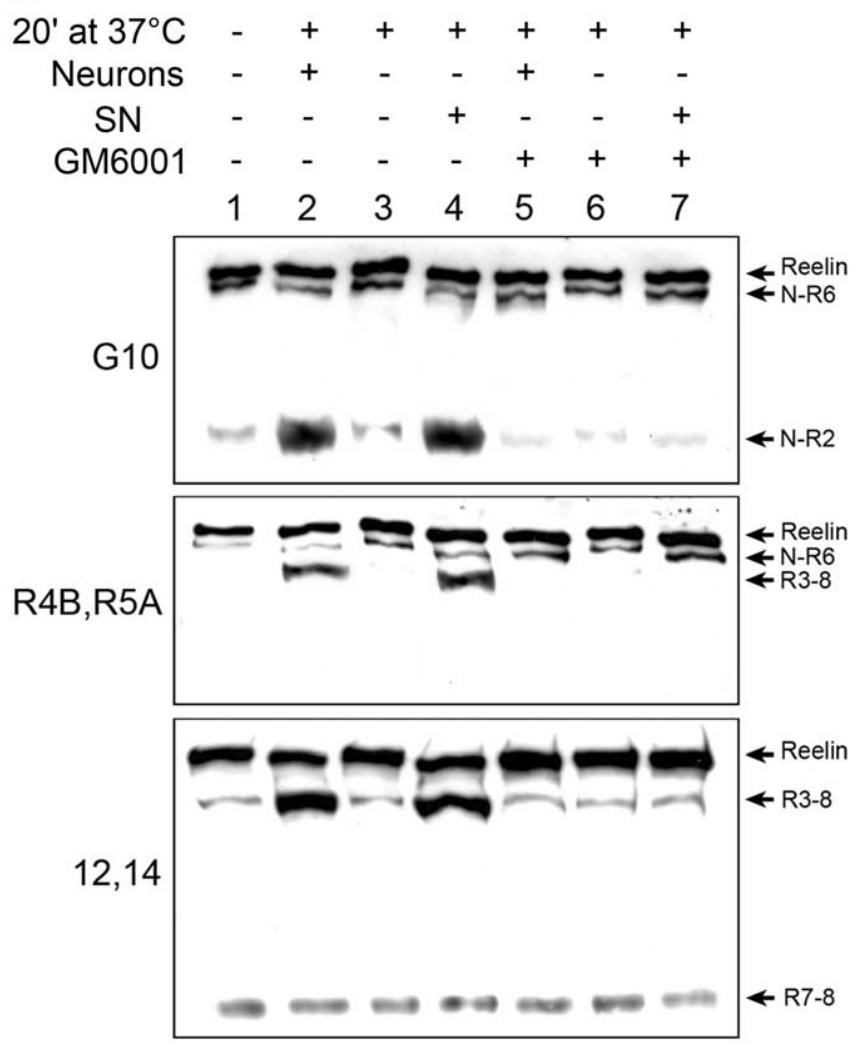

B

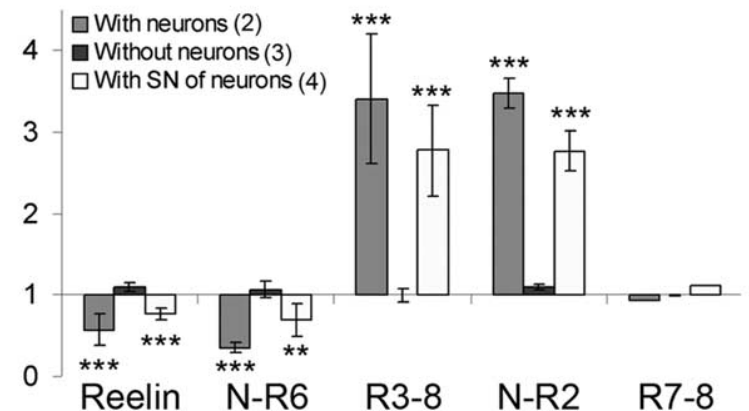

Figure 4. Cleavage of Reelin by a metalloproteinase secreted by cultured neurons. $A$, Western blot analysis with antibodies $\mathrm{G10}$, R4B,R5A, and 12,14, of full-length Reelin at time 0 (lane 1) and after incubation with cultured neurons (lanes 2,5), with culture medium alone (lanes 3 , 6), or with the supernatant of these neurons (lanes 4,7$)$. Incubation was performed without (lanes 2-4) and with (lanes 5-7) the metalloproteinase inhibitor GM6001 at $80 \mu \mathrm{M}$. B, Densitometric analysis of three independent experiments performed without GM6001. Signals are expressed relatively to those in lane 1, corresponding to the native Reelin preparation, as mean \pm SEM. ${ }^{* *} p<0.01$ (Student's $t$ test); ${ }^{* * *} p<0.001$, significantly different. SN, Supernatant.

of full-length Reelin (supernatants from HEK293T cells transfected with the full-length Reelin cDNA) consistently displayed basal processing (Fig. $4 A$, lane 1). In the presence of cortical neurons, the concentrations of N-terminal Reelin and R3-8 increased dramatically, whereas that of the full-length and N-R6 proteins decreased and that of fragment R7-8 remained relatively unchanged, indicating increased cleavage at the $\mathrm{N}$-terminal but not at the C-terminal site (Fig. 4A, compare lanes 2, 3; quantification in Fig. 4B). A similar pattern was observed when Reelin was incubated with the supernatant from cultured neurons (Fig. $4 A$, lane 4; quantification in Fig. $4 B$ ), but processing was abrogated in the presence of the metalloproteinase inhibitor GM6001
(Fig. 4A, lanes 5-7). These results indicate that cleavage at the $\mathrm{N}$-terminal site is performed by a metalloproteinase secreted by cultured embryonic neurons and that cleavage at the $\mathrm{N}$ and $\mathrm{C}$ sites may occur independently.

\section{Processing does not affect signaling and internalization in dissociated neurons in culture}

Using antibodies $\mathrm{R} 4 \mathrm{~B}$ and $\mathrm{R} 5 \mathrm{~A}$ to adjust concentrations, we tested whether processing of Reelin modifies its capacity to stimulate Dab1 phosphorylation in cultured dissociated neurons, and we compared the internalization of recombinant Reelin proteins in neurons. Similar concentrations of full-length Reelin, R3-8, R3-6, and N-R6 were equally able to stimulate Dab1 phosphorylation in neurons (Jossin et al., 2004). Because full-length Reelin was rapidly cleaved at the $\mathrm{N}$-terminal site when added to neurons, Dab1 phosphorylation assays were repeated in the presence of GM6001, with similar results (Fig. 5A). Thus, inhibition of Reelin processing did not affect biological activity when tested on neurons. To study ligand internalization, cortical neurons were incubated with full-length, R3-6, or N-R2 recombinant Reelins, for $10 \mathrm{~min}$ at $37^{\circ} \mathrm{C}$, conditions that allow endocytosis of Reelin (D'Arcangelo et al., 1999; Morimura et al., 2005), and at $4^{\circ} \mathrm{C}$ as control. In contrast to the $\mathrm{N}$-terminal fragment N-R2, which did not enter cells, full-length Reelin and recombinant R3-6 were internalized similarly, indicating that both proteins follow similar intracellular routes when presented to dissociated cultured neurons in vitro. No Reelin internalization was detected in neurons from VLDLR-/-; ApoER2 $-/-$ mutant cortices, confirming that internalization is receptor mediated (Fig. 5B).

\section{The generation of central Reelin is required for signaling in tissue}

When E13 embryonic brain slices were cultured in the presence of the metalloproteinase inhibitor GM6001, a disorganized CP developed (Fig. 6A). In slices from wild-type embryos pulsed with BrdU at E13, $2 \mathrm{~h}$ before culture, several BrdU-positive cells migrated beyond the Tbr1-positive neurons that were generated earlier. In contrast, in slices cultured in the presence of GM6001, like in reeler slices, no BrdU-labeled cells migrated beyond Tbr1positive cells (Fig. 6A). Moreover, when preplate cells were labeled with BrdU in vivo at E10, the splitting of the preplate was observed in slices prepared from wild-type brains, but not in wild-type slices treated with GM6001, that developed like reeler slices (Fig. 6B). Slices cultured in the presence of the GM6001negative control developed normally, confirming that the effects of GM6001 are attributable to inhibition of metalloproteinase activity (data not shown). Although inhibition of metalloproteinases in brain slices decreased strongly Reelin processing, the presence of some Reelin fragments in the supernatant from GM6001-treated slices indicated that processing was not completely blocked (Fig. 6C). Presumably, GM6001-resistant enzymes expressed in the organotypic culture may be responsible for residual processing activity. Yet, even the partial inhibition of cleavage downregulated Reelin signaling significantly, as indicated by decreased Dab1 phosphorylation after $4 \mathrm{~h}$ and upregulation of Dabl protein concentration after $24 \mathrm{~h}$ (Fig. 6D) (Rice and Curran, 2001; Jossin et al., 2004). Thus, in brain slice culture, blocking Reelin processing perturbs CP development and impairs Reelin signaling.

To further investigate whether central Reelin is important for signaling in tissue, we analyzed brain extracts from wild-type and mutant mice defective in Dab1, VLDL, and ApoER2 receptors. 
The concentration of central Reelin was similarly low in extracts from wild-type Dab1 mutant (both null and scrambler) brains, as well as from VLDLR-/-; ApoER2 $+/-$ tissue. In contrast, it was dramatically increased in tissues from double receptor (VLDLR-/-; ApoER2-/-) mutant mice. The relative concentrations of all other Reelin forms were similar in all genotypes (Fig. 7). This result provides strong evidence that, in vivo, central Reelin binds preferentially to receptors and is selectively degraded.

\section{Discussion}

Antibodies R4B and R5A, directed against epitopes in the central region of Reelin, allow detection of the predicted central processing fragment in tissue extracts and CSF and block signaling, confirming the pivotal role of central Reelin (Jossin et al., 2004). We also provide evidence that processing of Reelin is important for function in vivo. Embryonic neurons in culture secrete a metalloproteinase activity that processes Reelin. Inhibition of cleavage does not affect Reelin signaling in cultured dissociated neurons, which are able to internalize full-length and central Reelin similarly. In contrast, inhibition of metalloproteinases in organotypic brain slice cultures inhibits Reelin cleavage and signaling and disturbs the formation of the CP. Furthermore, the relative concentration of central Reelin is dramatically increased in brains from mice deficient in VLDL and ApoER2 receptors, indicating that this fragment is preferentially internalized by target cells in vivo. To resolve the apparent discrepancy between observations in tissue and in cultured neurons, we propose that, in tissue, full-length Reelin cannot diffuse freely because it is anchored to the ECM and that metalloproteinases secreted by migrating neurons liberate central Reelin that diffuses toward and activates signaling in target cells (Fig. 8). Below, we discuss briefly the role of central versus N-terminal Reelin, Reelin endocytosis, and some implications of the proposed model.

Previous studies with antibodies against the $\mathrm{N}$ - and C-terminal regions of Reelin showed that several fragments are present in brain extracts, CSF, and plasma (Lambert de Rouvroit et al., 1999; Smalheiser et al., 2000; Ignatova et al., 2004). The pattern observed indicated that Reelin is cleaved at two sites located, respectively, C-terminal to repeats 2 and 6 . However, available reagents did not allow detection of the central predicted fragment that we now characterize directly. Central Reelin is necessary and sufficient to bind to VLDL and ApoER2 receptors, to induce phosphorylation of Dab1, and

A

B

+ GM6001
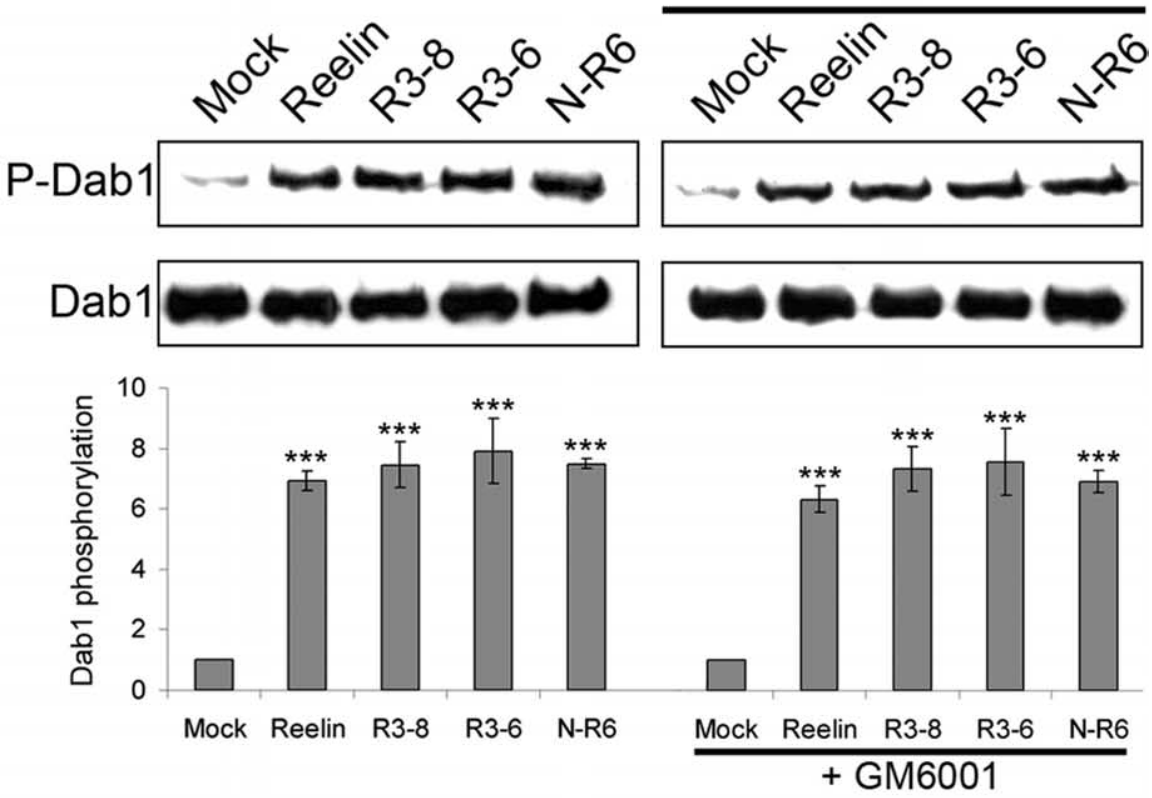

Reelin
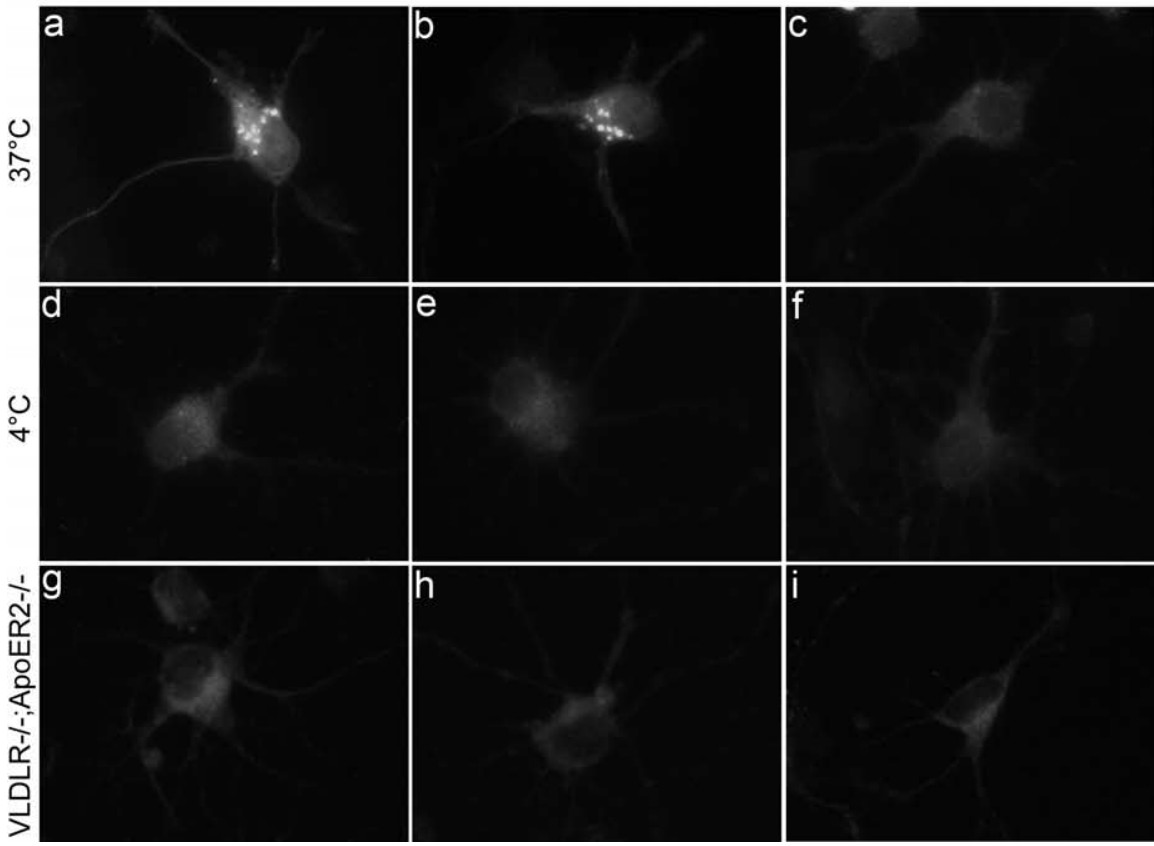

Figure 5. Processing does not affect signaling and internalization in dissociated neurons in culture. $A$, Comparison of Dab1 tyrosine phosphorylation ( $\mathrm{P}$-Dab1) induced in primary neurons by Reelin and various recombinant proteins containing the active central fragment. Similar results are obtained in the absence or presence of $80 \mu \mathrm{M}$ GM6001. The graph shows the densitometric analysis of three independent experiments. Signals are expressed relative to the control experiments, performed by the addition of mock supernatant, as mean \pm SEM. ${ }^{* * *} p<0.001$, significantly different (Student's $t$ test). $\boldsymbol{B}$, E16.5 cortical reeler neurons were cultured for $3 \mathrm{~d}$ before the addition of Reelin $(\boldsymbol{a}, \boldsymbol{d}), \mathrm{R} 3-6(\boldsymbol{b}, \boldsymbol{e})$, or N-R2 $(\boldsymbol{c}, \boldsymbol{f})$, for 10 min at $37^{\circ} \mathrm{C}(\boldsymbol{a}-\boldsymbol{c})$ or at $4^{\circ} \mathrm{C}$ for control experiments $(\boldsymbol{d}-\boldsymbol{f})$. Internalized proteins are detected in endocytic vesicles with the $\mathrm{N}$-terminal anti-Reelin $\mathrm{E} 4(\boldsymbol{a}, \boldsymbol{c}, \boldsymbol{d}, \boldsymbol{f})$ or with antibody R4B $(\boldsymbol{b}, \boldsymbol{e})$. This internalization is not detected when Reelin is added to neurons from VLDLR $-/-$ and ApoER2 $-/-$ mutant mice $(\boldsymbol{g}-\boldsymbol{i})$. to rescue the organization of the $\mathrm{CP}$ in organotypic brain slices from reeler mutant embryos (Jossin et al., 2004). Here, we also demonstrate that, by preventing binding of Reelin to VLDLR and ApoER2, antibodies R4B and R5A block all known functions of Reelin during early cortical development. This provides addi- 

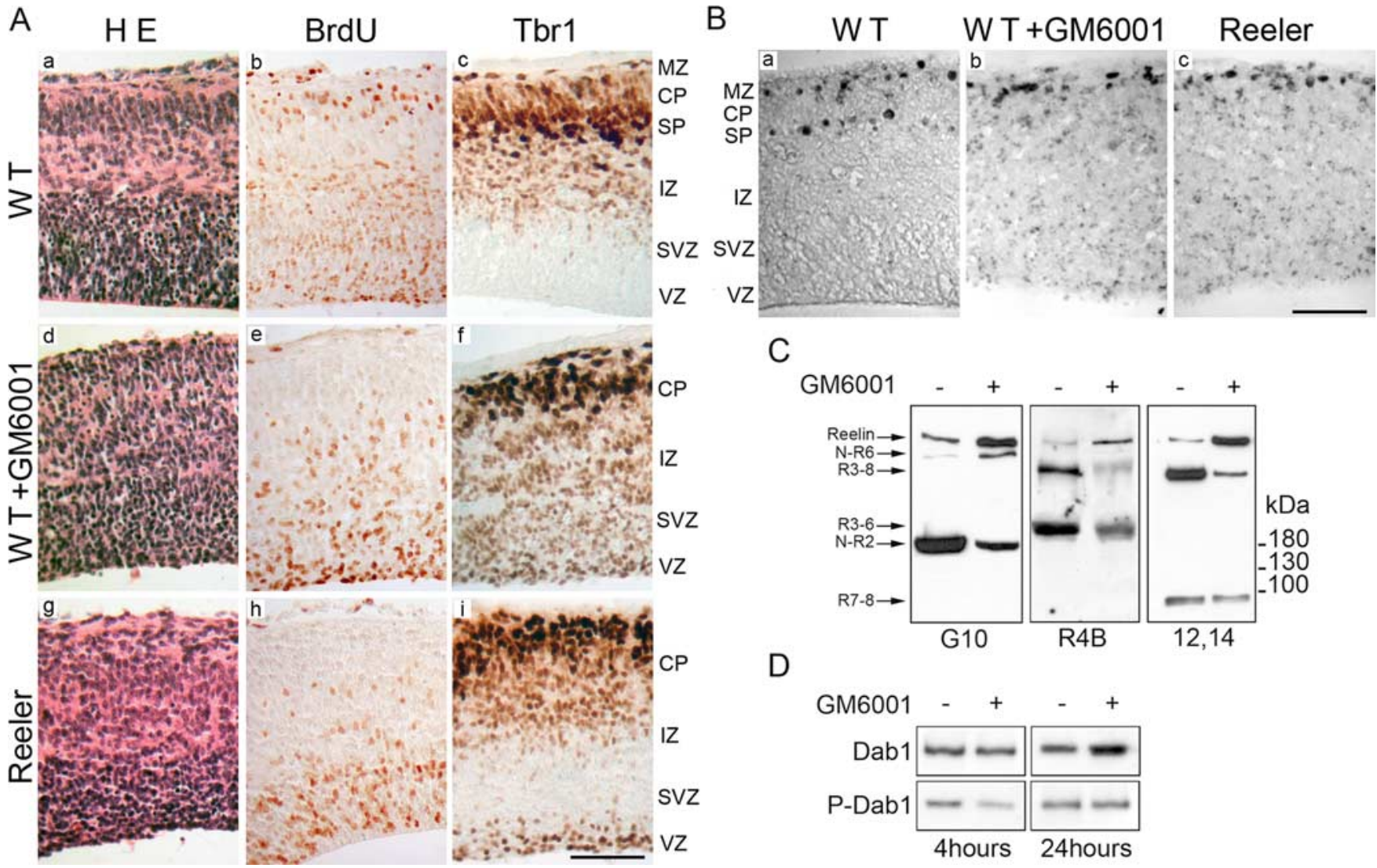

Figure 6. Metalloproteinases are important for (P formation $(\boldsymbol{A})$, preplate splitting $(\boldsymbol{B})$, and Reelin signaling $(\boldsymbol{C}, \boldsymbol{D})$. $\boldsymbol{A}$, Slices from 13-d-old wild-type embryonic brains were cultured for $2 \mathrm{~d}$ with or without $80 \mu \mathrm{m}$ GM6001. $\boldsymbol{a}$, Development proceeds normally in the absence of the inhibitor, with a radially organized, dense CP bracketed by a clearly defined MZ and subplate. $\boldsymbol{b}, \boldsymbol{c}$, Several neurons labeled by a BrdU pulse $2 \mathrm{~h}$ before slice preparation $(\boldsymbol{b})$ are able to migrate past older Tbr1-positive neurons ( $\boldsymbol{c}$, reflecting a normal inside-to-outside layering. $\boldsymbol{d}$ - $\boldsymbol{i}$, In slices incubated with GM6001, the developing $(P$ is disorganized, the cell-poor MZ is absent $(\boldsymbol{d})$, and layering is inverted $(\boldsymbol{e}, \boldsymbol{f})$, a phenotype reminiscent of that in slices prepared from reeler mutant embryos $(\boldsymbol{g}-\boldsymbol{i})$. Scale bar, 100 $\mu \mathrm{m} . \boldsymbol{B}$, BrdU was administered in vivo at E10, and brain slices were prepared at E13 and cultured for $2 \mathrm{~d}$. In wild-type slices, BrdU-positive cells are located in the MZ and the subplate, illustrating the splitting of the preplate $(\boldsymbol{a})$, whereas in wild-type slices incubated in the presence of GM6001, BrdU-positive cells migrate in the subpial region $(\boldsymbol{b})$ like in reeler slices $(\boldsymbol{c})$, demonstrating defective preplate splitting. Scale bar, $100 \mu \mathrm{m}$. C, Supernatants from E13 brain slices cultured for $2 \mathrm{~d}$ with or without GM6001 were analyzed by Western blot with anti-Reelin antibodies G10, R4B, or 12+ 14. There is clear, albeit incomplete, inhibition of Reelin processing in supernatant from slices cultured in the presence of the metalloproteinase inhibitor. D, Dab1, immunoprecipitated from E13 slices cultured for variable times with and without GM6001, was analyzed by Western blot using anti-Dab1 and anti-phosphotyrosine antibodies. The presence of GM6001 decreased the phosphorylation of Dab1 after $4 \mathrm{~h}$ of culture. After $24 \mathrm{~h}$, Dab1 phosphorylation was similar in slices incubated with or without GM6001, but the concentration of the Dab1 protein was increased in the presence of the inhibitor. WT, Wild type; SP, subplate; HE, hematoxylin and eosin staining; IZ, intermediate zone; SVZ, subventricular zone; VZ, ventricular zone.

tional argument for the crucial role of central Reelin, also underscored in a recent structural study (Nogi et al., 2006). On the other hand, numerous studies using the CR50 antibody (Ogawa et al., 1995) point to the importance of the N-terminal region. Although CR50 is directed against an epitope in the N-terminal region that is not engaged in binding to receptors (Hiesberger et al., 1999; Jossin et al., 2004), it counteracts the action of Reelin in various assays (Ogawa et al., 1995; Nakajima et al., 1997; D'Arcangelo et al., 1999; Utsunomiya-Tate et al., 2000; Hack et al., 2002; Kubo et al., 2002; Niu et al., 2004; Cariboni et al., 2005). At first sight, the blocking action of CR50 would predict that fragments of Reelin that do not contain the N-terminal region should have reduced biological activity, which is not what we observe. Several explanations can be proposed. Because CR50 cannot be used in Western blot and probably recognizes a configuration epitope, a cross-reaction with central Reelin is not formally excluded. Alternatively, fragments of Reelin could remain physically associated after cleavage, and CR50 might affect indirectly the structure of the central region in such complexes, or perturb receptor binding by steric hindrance. Finally, incubation with CR50 may hamper N-terminal processing and prevent the formation of the central fragment or its access to receptors on target cells. The functional role of central Reelin is also relevant to studies of Reelin in human pathology. Thus far, most analyses were performed using antibody 142 that detects an epitope in $\mathrm{N}$-terminal Reelin. Because extracellular Reelin is almost completely cleaved in tissue, conclusions in terms of function should be considered carefully and evaluated further by studies of central Reelin.

A main finding of the present work is that the concentration of central Reelin is dramatically increased in brains from double receptor mutant mice. This suggests strongly that production of central Reelin is required in tissue and that this fragment is downregulated in a receptor-dependent manner, presumably by endocytosis. In line with this, the central fragment is rapidly internalized by neurons in a receptor-dependent manner, whereas the $\mathrm{N}$-terminal fragment is not observed in intracellular vesicles. Full-length Reelin is also internalized, indicating that processing is not required for endocytosis. Thus, the selective clearance of the central fragment in vivo likely reflects preferential access to cells, rather than high affinity for receptors. The observation that the concentration of central Reelin is normal in Dab1 mutant 
tissue indicates that downregulation occurs in parallel to signaling. Because Dab1 regulates receptor trafficking (Morimura et al., 2005), this finding was somewhat unexpected. However, the reported effect of Dab1 on receptor expression and decreased Reelin uptake is moderate (Morimura et al., 2005), whereas a complete inactivation of both VLDLR and ApoER2 is absolutely required to generate a reelerlike phenotype (Trommsdorff et al., 1999) and to upregulate the concentration of central Reelin in vivo (Fig. 7). Presumably, compensation or adaptation of the trafficking process occurs during development, dampening subtle events that are demonstrated better in vitro. Like Dab1, adaptors implicated in endocytosis, such as ARH and Dab2, bind to the NPXY motif in the tail of Reelin receptors (Morris and Cooper, 2001; Jones et al., 2003; Cuitino et al., 2005; Maurer and Cooper, 2005; Stolt and Bock, 2006). The prompt degradation of Dab1 by the proteasome after Reelin signaling and Dab1 phosphorylation (Arnaud et al., 2003b; Bock et al., 2004) may facilitate their docking to receptors, followed by clathrinmediated clustering in coated pits and endocytosis.

The model schematized in Figure 8 posits that, after secretion, Reelin is anchored to the ECM and that the central fragment is released by metalloproteinase activities secreted by migrating neurons. ECM anchoring could occur via formation of Reelin oligomers or aggregates (Utsunomiya-Tate et al., 2000; Kubo et al., 2002), or by interaction with other ECM proteins. The observation that extracellular Reelin is detected in the CP with $\mathrm{N}$-terminal and central antibodies but not with C-terminal antibodies suggests that both the $\mathrm{N}$-terminal and central Reelin can diffuse after cleavage and that the $\mathrm{C}$ terminus might also contribute to ECM attachment. We have preliminary evidence that a high molecular weight component coimmunoprecipitates with Reelin in embryonic brain explants, but thus far no Reelin-binding ECM molecule has been identified. The concept that active fragments from proteins attached to the ECM are released by proteolytic processing is not new and was proposed, among others, for F-spondin (Tzarfaty-Majar et al., 2001), hepatocyte growth factor (Matsuoka et al., 2006), or transforming growth factor- $\beta$ (Dallas et al., 2002).

Although the implication of metalloproteinases in Reelin processing is established beyond reasonable doubt, several questions remain. The metalloproteinase responsible for the cleavage of Reelin at the N-terminal site is secreted by cortical cells in culture, but its identity and the sequence at the cleavage site remain unknown. In addition, processing is never fully prevented by metalloproteinase inhibitors in slice cultures, suggesting that other enzymes are able to process Reelin in some conditions. Cleavage at the C-terminal site may be performed by a different enzymatic activity (Lugli et al., 2003) that is even less characterized. Although our observations provide strong argument that processing is required for Reelin function in tissue, definitive proof awaits demonstration in vivo. As far as we know, no mouse with genetic inactivation of metalloproteinases has a reeler-like phenotype, but there is obvious redundancy among proteolytic enzymes, and multiple knockouts are often embryonic lethal, preventing manifestation of the reeler trait. A partial rescue of the reeler phenotype was achieved in transgenic mice that express full-length Reelin under control of the nestin promoter (Magdaleno et al., 2002). Our model would predict that such rescue will not happen in transgenic mice that express a cleavage-resistant Reelin, but the production of such mice also requires identification of the cleavage sites. 


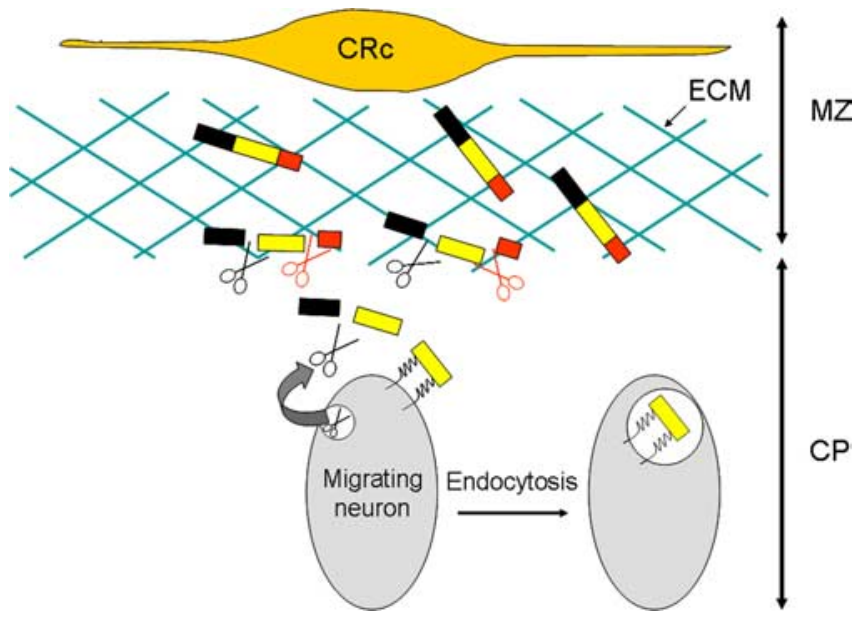

Figure 8. Model for the production and action of central Reelin in tissue. Reelin secreted by Cajal-Retzius cells (CRc) in the MZ is anchored to the ECM, probably by its N-terminal (black) and possibly C-terminal (red) regions. Processing at an $\mathrm{N}$-terminal site by a metalloproteinase secreted by migrating neurons (black scissors) and at a C-terminal site by an undefined enzyme (red scissors) generates N-terminal, C-terminal, and central (yellow) fragments. The central fragment is then free to bind to receptors at the leading edge of $C P$ neurons and undergoes endocytosis.

\section{References}

Alcantara S, Ruiz M, D’Arcangelo G, Ezan F, de Lecea L, Curran T, Sotelo C, Soriano E (1998) Regional and cellular patterns of reelin mRNA expression in the forebrain of the developing and adult mouse. J Neurosci 18:7779-7799.

Arnaud L, Ballif BA, Forster E, Cooper JA (2003a) Fyn tyrosine kinase is a critical regulator of Disabled-1 during brain development. Curr Biol 13:9-17.

Arnaud L, Ballif BA, Cooper JA (2003b) Regulation of protein tyrosine kinase signaling by substrate degradation during brain development. Mol Cell Biol 23:9293-9302.

Ausubel FM (2001) Current protocols in molecular biology. New York: Wiley.

Bar I, Tissir F, Lambert De Rouvroit C, De Backer O, Goffinet AM (2003) The gene encoding Disabled-1 (DAB1), the intracellular adaptor of the Reelin pathway, reveals unusual complexity in human and mouse. J Biol Chem 278:5802-5812.

Bock HH, Herz J (2003) Reelin activates SRC family tyrosine kinases in neurons. Curr Biol 13:18-26.

Bock HH, Jossin Y, May P, Bergner O, Herz J (2004) Apolipoprotein E receptors are required for reelin-induced proteasomal degradation of the neuronal adaptor protein Disabled-1. J Biol Chem 279:33471-33479.

Cariboni A, Rakic S, Liapi A, Maggi R, Goffinet A, Parnavelas JG (2005) Reelin provides an inhibitory signal in the migration of gonadotropinreleasing hormone neurons. Development 132:4709-4718.

Caviness Jr VS (1982) Neocortical histogenesis in normal and reeler mice: a developmental study based upon $[3 \mathrm{H}]$ thymidine autoradiography. Brain Res 256:293-302.

Cuitino L, Matute R, Retamal C, Bu G, Inestrosa NC, Marzolo MP (2005) ApoER2 is endocytosed by a clathrin-mediated process involving the adaptor protein Dab2 independent of its Rafts' association. Traffic 6:820-838.

Dallas SL, Rosser JL, Mundy GR, Bonewald LF (2002) Proteolysis of latent transforming growth factor-beta (TGF-beta)-binding protein- 1 by osteoclasts. A cellular mechanism for release of TGF-beta from bone matrix. J Biol Chem 277:21352-21360.

D’Arcangelo G, Miao GG, Chen SC, Soares HD, Morgan JI, Curran T (1995) A protein related to extracellular matrix proteins deleted in the mouse mutant reeler. Nature 374:719-723.

D’Arcangelo G, Homayouni R, Keshvara L, Rice DS, Sheldon M, Curran T (1999) Reelin is a ligand for lipoprotein receptors. Neuron 24:471-479.

de Bergeyck V, Nakajima K, Lambert de Rouvroit C, Naerhuyzen B, Goffinet AM, Miyata T, Ogawa M, Mikoshiba K (1997) A truncated Reelin pro- tein is produced but not secreted in the 'Orleans' reeler mutation (Reln[rl-Orl]). Brain Res Mol Brain Res 50:85-90.

de Bergeyck V, Naerhuyzen B, Goffinet AM, Lambert de Rouvroit C (1998) A panel of monoclonal antibodies against reelin, the extracellular matrix protein defective in reeler mutant mice. J Neurosci Methods 82:17-24.

Hack I, Bancila M, Loulier K, Carroll P, Cremer H (2002) Reelin is a detachment signal in tangential chain-migration during postnatal neurogenesis. Nat Neurosci 5:939-945.

Hiesberger T, Trommsdorff M, Howell BW, Goffinet A, Mumby MC, Cooper JA, Herz J (1999) Direct binding of Reelin to VLDL receptor and ApoE receptor 2 induces tyrosine phosphorylation of disabled-1 and modulates tau phosphorylation. Neuron 24:481-489.

Hong SE, Shugart YY, Huang DT, Shahwan SA, Grant PE, Hourihane JO, Martin ND, Walsh CA (2000) Autosomal recessive lissencephaly with cerebellar hypoplasia is associated with human RELN mutations. Nat Genet 26:93-96.

Howell BW, Hawkes R, Soriano P, Cooper JA (1997) Neuronal position in the developing brain is regulated by mouse disabled-1. Nature 389:733-737.

Howell BW, Herrick TM, Cooper JA (1999) Reelin-induced tryosine phosphorylation of disabled 1 during neuronal positioning. Genes Dev 13:643-648.

Ignatova N, Sindic CJ, Goffinet AM (2004) Characterization of the various forms of the Reelin protein in the cerebrospinal fluid of normal subjects and in neurological diseases. Neurobiol Dis 15:326-330.

Jones C, Hammer RE, Li WP, Cohen JC, Hobbs HH, Herz J (2003) Normal sorting but defective endocytosis of the low density lipoprotein receptor in mice with autosomal recessive hypercholesterolemia. J Biol Chem 278:29024-29030.

Jossin Y (2004) Neuronal migration and the role of reelin during early development of the cerebral cortex. Mol Neurobiol 30:225-251.

Jossin Y, Ogawa M, Metin C, Tissir F, Goffinet AM (2003) Inhibition of SRC family kinases and non-classical protein kinases $\mathrm{C}$ induce a reeler-like malformation of cortical plate development. J Neurosci 23:9953-9959.

Jossin Y, Ignatova N, Hiesberger T, Herz J, Lambert de Rouvroit C, Goffinet AM (2004) The central fragment of Reelin, generated by proteolytic processing in vivo, is critical to its function during cortical plate development. J Neurosci 24:514-521.

Kubo K, Mikoshiba K, Nakajima K (2002) Secreted Reelin molecules form homodimers. Neurosci Res 43:381-388.

Kuo G, Arnaud L, Kronstad-O’Brien P, Cooper JA (2005) Absence of Fyn and Src causes a reeler-like phenotype. J Neurosci 25:8578-8586.

Lambert de Rouvroit C, de Bergeyck V, Cortvrindt C, Bar I, Eeckhout Y, Goffinet AM (1999) Reelin, the extracellular matrix protein deficient in reeler mutant mice, is processed by a metalloproteinase. Exp Neurol 156:214-217.

Lugli G, Krueger JM, Davis JM, Persico AM, Keller F, Smalheiser NR (2003) Methodological factors influencing measurement and processing of plasma reelin in humans. BMC Biochem 4:9.

Magdaleno S, Keshvara L, Curran T (2002) Rescue of ataxia and preplate splitting by ectopic expression of Reelin in reeler mice. Neuron 33:573-586.

Matsuoka H, Sisson TH, Nishiuma T, Simon RH (2006) Plasminogenmediated activation and release of hepatocyte growth factor from extracellular matrix. Am J Respir Cell Mol Biol 35:705-713.

Maurer ME, Cooper JA (2005) Endocytosis of megalin by visceral endoderm cells requires the Dab2 adaptor protein. J Cell Sci 118:5345-5355.

Morimura T, Hattori M, Ogawa M, Mikoshiba K (2005) Disabled1 regulates the intracellular trafficking of reelin receptors. J Biol Chem 280:16901-16908.

Morris SM, Cooper JA (2001) Disabled-2 colocalizes with the LDLR in clathrin-coated pits and interacts with AP-2. Traffic 2:111-123.

Nakajima K, Mikoshiba K, Miyata T, Kudo C, Ogawa M (1997) Disruption of hippocampal development in vivo by CR-50 mAb against reelin. Proc Natl Acad Sci USA 94:8196-8201.

Niu S, Renfro A, Quattrocchi CC, Sheldon M, D’Arcangelo G (2004) Reelin promotes hippocampal dendrite development through the VLDLR/ ApoER2-Dab1 pathway. Neuron 41:71-84.

Nogi T, Yasui N, Hattori M, Iwasaki K, Takagi J (2006) Structure of a signaling-competent reelin fragment revealed by X-ray crystallography and electron tomography. EMBO J 25:3675-3683. 
Ogawa M, Miyata T, Nakajima K, Yagyu K, Seike M, Ikenaka K, Yamamoto H, Mikoshiba K (1995) The reeler gene-associated antigen on CajalRetzius neurons is a crucial molecule for laminar organization of cortical neurons. Neuron 14:899-912.

Rice DS, Curran T (2001) Role of the reelin signaling pathway in central nervous system development. Annu Rev Neurosci 24:1005-1039.

Schiffmann SN, Bernier B, Goffinet AM (1997) Reelin mRNA expression during mouse brain development. Eur J Neurosci 9:1055-1071.

Sheldon M, Rice DS, D’Arcangelo G, Yoneshima H, Nakajima K, Mikoshiba K, Howell BW, Cooper JA, Goldowitz D, Curran T (1997) Scrambler and yotari disrupt the disabled gene and produce a reeler-like phenotype in mice. Nature 389:730-733.

Smalheiser NR, Costa E, Guidotti A, Impagnatiello F, Auta J, Lacor P, Kriho V, Pappas GD (2000) Expression of reelin in adult mammalian blood, liver, pituitary pars intermedia, and adrenal chromaffin cells. Proc Natl Acad Sci USA 97:1281-1286.

Stolt PC, Bock HH (2006) Modulation of lipoprotein receptor functions by intracellular adaptor proteins. Cell Signal 18:1560-1571.
Tissir F, Goffinet AM (2003) Reelin and brain development. Nat Rev Neurosci 4:496-505.

Trommsdorff M, Gotthardt M, Hiesberger T, Shelton J, Stockinger W, Nimpf J, Hammer RE, Richardson JA, Herz J (1999) Reeler/Disabled-like disruption of neuronal migration in knockout mice lacking the VLDL receptor and ApoE receptor 2. Cell 97:689-701.

Tzarfaty-Majar V, Lopez-Alemany R, Feinstein Y, Gombau L, Goldshmidt O, Soriano E, Munoz-Canoves P, Klar A (2001) Plasmin-mediated release of the guidance molecule F-spondin from the extracellular matrix. J Biol Chem 276:28233-28241.

Utsunomiya-Tate N, Kubo K, Tate S, Kainosho M, Katayama E, Nakajima K, Mikoshiba K (2000) Reelin molecules assemble together to form a large protein complex, which is inhibited by the function-blocking CR-50 antibody. Proc Natl Acad Sci USA 97:9729-9734.

Ware ML, Fox JW, Gonzalez JL, Davis NM, Lambert de Rouvroit C, Russo CJ, Chua Jr SC, Goffinet AM, Walsh CA (1997) Aberrant splicing of a mouse disabled homolog, mdab1, in the scrambler mouse. Neuron 19: 239-249. 